\title{
ANALISIS PERFORMANSI AGREGASI LINK DENGAN LACP PADA SDN MENGGUNAKAN RYU SEBAGAI CONTROLLER
}

\author{
Rohmat Tulloh \\ Program Studi D3 Teknik Telekomunikasi, Fakultas Ilmu Terapan, Universitas Telkom \\ Corresponding author, e-mail: rohmatth@telkomuniversity.ac.id
}

\begin{abstract}
Abstrak-Dunia telekomunikasi saat ini berkembang dengan sangat pesat terutama dalam dunia jaringan. Salah satu teknologi jaringan masa kini adalah SDN (Software Defined Network) yaitu sebuah paradigma baru dalam teknologi jaringan yang dapat memvirtualisasi perangkat jaringan dengan mengambil fungsi control plane oleh controller dan memisahkan antara control plane dengan data plane dalam sebuah perangkat jaringan. Selain adanya paradigma baru tersebut, kebutuhan akan konsumsi bandwidth dalam komunikasi data saat ini juga meningkat. Link aggregation merupakan metode penggabungan link fisik menjadi satu link logis guna meningkatkan kapasitas bandwidth. Link aggregation dapat di implementasikan dalam jaringan SDN, hal ini membuat konsumsi sejumlah bandwidth pada jaringan berdampak baik terhadap kualitas layanan pada jaringan. Dalam penelitian ini, ditunjukkan analisis perbandingan terhadap jaringan SDN yang menggunakan metode link aggregation dengan jaringan SDN yang tanpa metode link aggregation. Analisis ini memperhatikan hasil pengukuran throughput, packet loss, jitter dan fault tolerant dari layanan video streaming pada jaringan.
\end{abstract}

\section{Kata Kunci : SDN, Link aggregation, LACP, Redundansi, Bandwith.}

\begin{abstract}
As time goes by, the world of communication has flourished quickly, especially in network. One of the network technologies by now called SDN (Software Defined Network), is a new paradigm in network technology that is able to virtualize network device by taking the function of control plane, that is usually taken by controller, and separate between control plane and data plane into a network device. Besides the coming of that new paradigm, the need of bandwidth consumption on data communication by this time has increased. Link aggregation is a method that combines several physical links into a logical link in the form of multiplying the bandwidth capacity. Link aggregation can be implemented in SDN network, that makes bandwidth consumption in network has good effect on service quality. In this research, the writer will show the comparison analysis between link aggregation and not using link aggregation in SDN network. This comparison analysis is done by analyzing some parameters, like throughput, packetloss, jitter and fault tolerance from the service in network, called video streaming.
\end{abstract}

Keywords : SDN, Link aggregation, LACP, Redundansi, Bandwith.

Copyright $@ 2017$ JNTE. All rights reserved

\section{PENDAHULUAN}

Jaringan komputer dan data terdiri atas tiga macam plane yang masing-masing memiliki fungsi khusus, yakni data plane yang berfungsi untuk meneruskan paket data (forwarding), control plane yang berfungsi untuk mengatur forwarding table yang menjadi acuan data plane untuk meneruskan paket data, dan management plane yang menyediakan layanan-layanan berupa software.

Jaringan komputer konvensional memiliki control plane dan data plane yang terikat dalam sebuah perangkat. Hal ini merupakan konsep yang disengaja pada masa-masa awal Internet berkembang untuk menjamin ketahanan (resilience) jaringan. Namun dengan berjalannya waktu dan meningkatnya kompleksitas kebutuhan pengguna akan layanan telekomunikasi data, konsep ini dirasa menjadi faktor besar dalam menghambat inovasi layananan, fitur perangkat dan memberatkan dari sisi efisiensi dan efektifitas serta menghasilkan arsitektur jaringan yang semakin kompleks.

Software-Defined Network (SDN) merupakan suatu paradigma baru dalam jaringan telekomunikasi data yang memisahkan control plane dari perangkat jaringan ke dalam suatu perangkat eksternal yang disebut controller, sehingga perangkat switch yang hanya sematamata berfungsi sebagai forwarding devices. 
Dalam implementasinya, dibutuhkan suatu API (Application Programming Interface) yang menghubungkan antara switch dan SDN Controller, contohnya adalah OpenFlow [1]. Dalam suatu switch OpenFlow terdapat banyak rules table yang mengatur bagaimana suatu paket yang masuk ke dalam switch diolah. Kebanyakan vendor perangkat jaringan telekomunikasi sudah memasukkan OpenFlow API ke dalam perangkat baru mereka.

Selain itu, semakin kompleksnya kebutuhan masyarakat saat ini menuntut suatu jaringan telekomunikasi bersifat high availability, biaya relatif murah, kecepatan tinggi, dan memiliki kapasitas yang besar diluar keterbatasan perangkat. Untuk mendukung hal tersebut maka perlu juga ada penambahan ketersediaan bandwidth. Diharapkan dengan penambahan bandwidth, maka layanan yang disediakan akan bertambah banyak. Untuk menjaga berbagai layanan tersebut tidak cukup hanya menggunakan satu gateway, jika gateway tersebut "down" maka koneksi terputus sehingga kegiatan yang memerlukan jaringan internet menjadi terhambat.

Link aggregation adalah metode penggabungan link fisik menjadi satu link logis untuk meningkatkan kapasitas bandwidth. Link aggregation mampu meningkatkan kapasitas dan ketersediaan saluran komunikasi antara perangkat yang menggunakan teknologi Fast Ethernet dan Gigabit Ethernet. Link aggregation juga menyediakan di mana pengolahan dan komunikasi aktivitas didistribusikan di beberapa link sehingga tidak ada link tunggal yang kewalahan menangani trafik. Fungsi lain dari link aggregation adalah menyediakan redundansi ketika salah satu link fisik putus, dimana fitur redundansi terbatas untuk perangkat jaringan standar [2]. Link aggregation diatur oleh standar IEEE 802.3ad [3].

Fungsi lain dari link aggregation adalah dapat menaikkan kecepatan koneksi antara switch dengan router, kemudian koneksi sesama switch serta koneksi server dengan router. Apabila terjadi kerusakan pada salah satu port maka akan menggunakan port yang lain dalam port group yang sama untuk menjaga sistem tetap bekerja [4]. Sehingga ditawarkan solusi untuk mengoptimasikan redundansi dan jaringan yang mampu melakukan load balancing sehingga paket yang dikirim lebih efektif dengan menggunakan LACP (Link aggregation Control Protocol) [5].

Penelitian ini bertujuan untuk mengukur dan menganalisis performansi jaringan dengan dan tanpa link aggregation dilakukan.

\section{PENELITIAN TERKAIT DAN KONTRIBUSI}

Pada [6], penulis melakukan implementasi link aggregation di jaringan VLAN yang diintegrasikan dengan algoritma round-robin. Penelitian ini menggunakan jaringan konvensional sehingga membutuhkan perangkat keras lain seperti router Mikrotik.

Pada [7], penulis meneliti mengenai kelebihan link aggregation beserta fungsi dan tipe dari link aggregation serta menjelaskan mengenai konfigurasi LACP pada SysConnect yang memungkinkan load balancing dengan informasi data berbasis IP, TCP dan UDP. Penulis masih mengimplementasikan LACP pada jaringan konvensional.

Pada [8], penulis menawarkan pengimplementasian LACP di jaringan SDN dengan topologi yang digunakan adalah spanning tree dan Floodlight sebagai controllernya. Paper ini hanya memberikan ide/gagasan, tidak terdapat hasil simulasi LACP yang ditawarkan.

Pada penelitian ini, penulis melakukan analisis performansi dari penggunaan protokol LACP pada jaringan SDN untuk layanan video streaming berbasis UDP dengan protokol MPEG. Parameter performansi yang dianalisis adalah throughput, jitter dan packetloss.

\section{TINJAUAN PUSTAKA}

\subsection{Software Defined Network (SDN)}

Jaringan IP tradisional yang memiliki konsep pengikatan control plane dan data plane dalam satu perangkat jaringan terbukti menghambat inovasi fitur layanan dalam jaringan, menghasilkan arsitektur jaringan yang semakin kompleks, untuk diatur dan bersifat statis [9], [10]. Selain itu kesalahan konfigurasi perangkat jaringan sudah merupakan hal yang umum saat ini, sebagai contoh terdapat lebih dari 1000 kesalahan konfigurasi yang berhasil diselidiki pada perangkat router BGP [11]. Kesalahan konfigurasi dalam suatu perangkat 
jaringan bisa mempengaruhi pola forwarding, packet loss atau bahkan membuat suatu layanan menjadi tidak berfungsi. Menurut statistik yang ada, kesalahan sebuah perangkat jaringan bisa mengganggu operasi seluruh jaringan Internet selama berjam-jam [12].

Setiap vendor perangkat jaringan menyediakan solusi atas sebuah fitur layanan jaringan yang memiliki paten, yang bisa digunakan dan diaplikasikan untuk perangkat, sistem operasi dan aplikasi jaringan yang merupakan produksi vendor tersebut. Akibatnya, operator jaringan yang menggunakan berbagai macam perangkat dari vendor berbeda perlu mempelajari solusi-solusi yang disediakan vendor-vendor tersebut dan bahkan membentuk suatu tim khusus untuk menangani perangkat dari masing-masing vendor. Tentu saja, biaya oeprasional untuk maintenance menjadi besar bagi operator jaringan.

Software-Defined Network (SDN) adalah suatu paradigma baru dalam jaringan, dimana data plane dikontrol oleh control plane yang bersifat remote dan tidak lagi terikat dalam perangkat jaringan. Gambar 1 menunjukkan arsitektur dari jaringan SDN dan perbedaannya dengan jaringan IP tradisional.

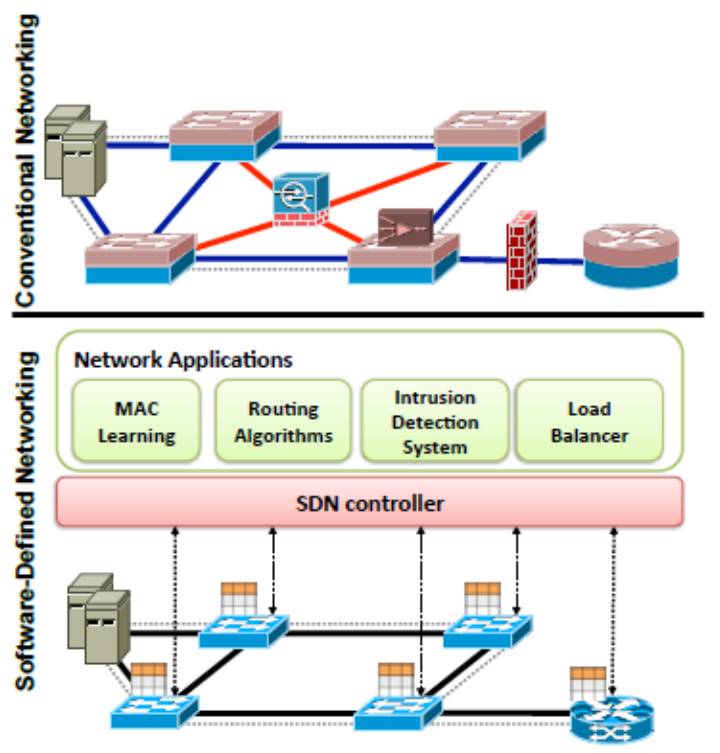

Gambar 1. Arsitektur SDN dibandingkan dengan jaringan tradisional [13]

Terdapat empat buah pilar utama yang membedakan jaringan SDN dengan jaringan IP tradisional [13], yaitu:
1. Pemisahan antara control plane dengan data plane. Fungsi kontrol dijalankan oleh perangkat eksternal sehingga perangkat jaringan hanya berfungsi untuk forwarding semata.

2. Keputusan forwarding data bersifat flowbased. Flow didefinisikan oleh kumpulan nilai packet field yang berfungsi sebagai filter dan sekumpulan aksi atau instruksi.

3. Logika kontrol berada pada perangkat eksternal yang disebut Network Operating System (NOS) atau yang lebih dikenal dengan SDN controller.

4. Jaringan dapat diprogram melalui aplikasi yang berjalan diatas NOS yang berinteraksi dengan perangkat pada level data plane.

Konsep SDN yang dinilai berprospek dan menjanjikan masa depan jaringan komputer dan data yang lebih baik berhasil membuat perusahan-perusahan besar yang bergerak di bidang ICT seperti Google, Facebook, Yahoo, Microsoft, Verizon, dan Deutsche Telekom turut berpartisipasi dalam riset yang diwadahi oleh Open Networking Foundation (ONF) [14]. Terdapat beberapa kelebihan akibat penggunaan SDN dalam jaringan, yaitu:

1. Memudahkan dalam melakukan pemrograman jaringan karena abstraksi yang disediakan oleh control platform dan bahasa pemrograman dapat dibagikan satu sama lain.

2. Seluruh aplikasi dapat mengambil informasi dalam jaringan sehingga keputusan forwarding dapat dilakukan secara konsisten dan efektif.

3. Re-konfigurasi perangkat jaringan dapat dilakukan dari bagian manapun dalam jaringan sehingga tidak perlu strategi khusus untuk menentukan lokasi fungsi baru.

4. Integrasi berbagai macam aplikasi dan fitur dalam jaringan dapat dilakukan dengan mudah, semisal menggabungkan load balancing dengan routing protocol.

\subsection{Link aggregation}

Link aggregation adalah suatu metode yang mengkombinasikan beberapa link fisik menjadi suatu link logika tunggal. Melalui link aggregation, kapasitas dan availability kanal antar perangkat meningkat dengan menggunakan teknologi Fast Ethernet dan Gigabit Ethernet saat ini. Link aggregation juga menyediakan fitur load balancing, dimana 
pemrosesan dan komunikasi data dilakukan pada beberapa link sehingga tidak terjadi suatu link yang kewalahan menangani trafik [7]. Standar dari link aggregation adalah IEEE 802.3ad. Gambar 2 menunjukkan contoh dari link aggregation dalam suatu arsitektur jaringan.

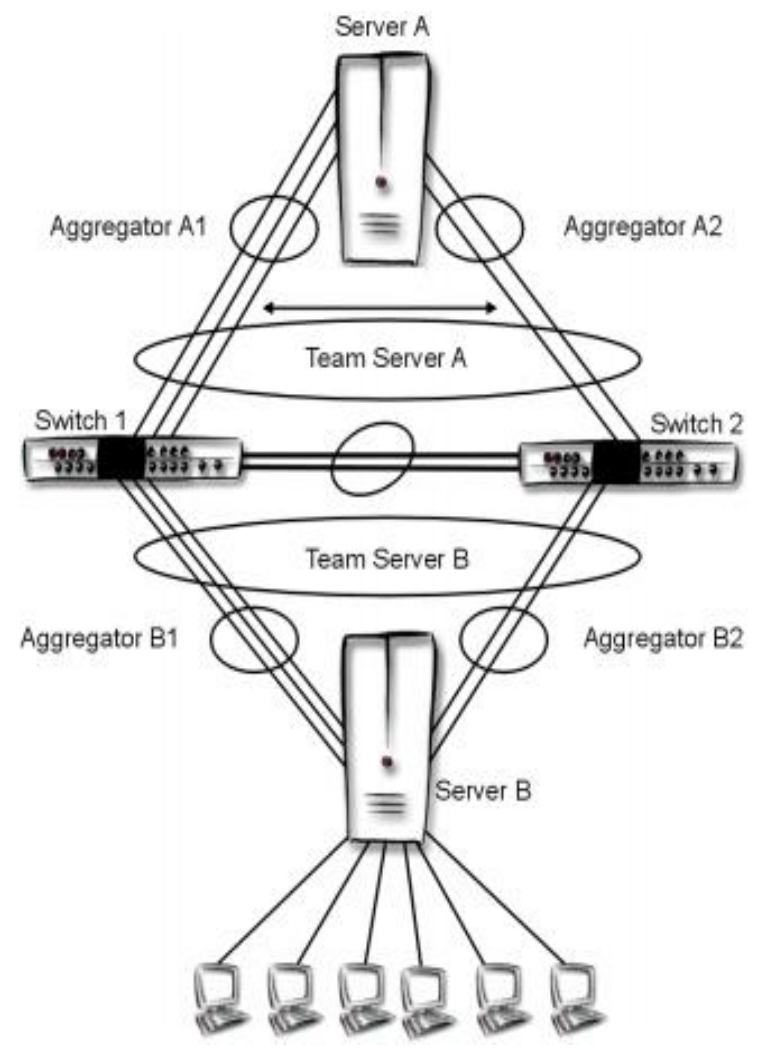

Gambar 2. Link aggregation dalam suatu arsitektur jaringan [7]

Untuk meningkatkan kapasitas link, ada dua cara yang dapat dilakukan yakni melakukan upgrade suatu link ke kapasitas yang lebih besar atau dengan melakukan agregasi dua atau lebih link yang memiliki kecepatan yang lebih rendah. Dengan menggunakan link aggregation, biaya yang diperlukan lebih rendah dibanding melakukan upgrade kecepatan link, dimana level performansi yang dihasilkan sama. Bahkan, link aggregation merupakan satu-satunya solusi untuk meningkatkan performa link ketika data rate tertinggi yang tersedia di pasaran tidak mencukupi [7].

Beberapa kelebihan yang ditawarkan dengan menggunakan link aggregation adalah sebagai berikut:
1. Link availability yang tinggi, komunikasi data akan tetap berlangsung meski salah satu link fisik putus.

2. Peningkatan kapasitas link.

3. Peningkatan performansi diperoleh dengan menggunakan perangkat keras saat itu juga (existing) sehingga tidak perlu melakukan upgrade perangkat yang membutuhkan biaya besar.

\subsection{LACP (Link aggregation Control Protocol)}

Saat ini, terdapat berbagai macam metode untuk melakukan agregasi link dengan tujuan meningkatkan throughput dan redundansi suatu link komunikasi. Terdapat dua jenis metode agregasi link, yaitu statis dan dinamis. Metode statis memerlukan suatu konfigurasi secara langsung ke setiap perangkat jaringan, sedangkan metode dinamis menggunakan LACP untuk memulai fungsi agregasi link secara dinamis [3].

LACP yang memiliki standar IEEE 802.1ax memungkinkan perangkat jaringan untuk mengimplementasikan LACP untuk melakukan bundling dari link secara otomatis melalui perukaran paket LACP [2]. Dibandingkan dengan metode dinamis, LACP menawarkan 2 kelebihan, yaitu:

1. Konfigurasi otomatis, dimana end device di sisi lain mampu menangani link aggregation.

2. Automatic failover, penanganan otomatis ketika terjadi kegagalan dalam link komunikasi, sehingga sistem tidak mengalami permasalahan sambungan.

\subsection{Ryu Controller}

Ryu adalah controller dalam SDN yang didesain untuk meningkatkan kecerdasan jaringan dengan memudahkan untuk mengatur suatu trafik data [7]. Secara umum, controller merupakan otak atau inti dari jaringan berbasis SDN yang mengatur komunikasi dengan switch dan router dengan menggunakan southbound APIs dan komunikasi dengan aplikasi dan logika bisnis dengan menggunakan northbound APIs.

Ryu menyediakan komponen perangkat lunak dengan API yang memudahkan developer untuk membuat manajemen jaringan baru, sehingga memudahkan organisasi bisnis untuk mencapai spesifikasi jaringan yang diinginkan. Gambar 3 menunjukkan arsitektur Ryu sebagai controller dari SDN. 


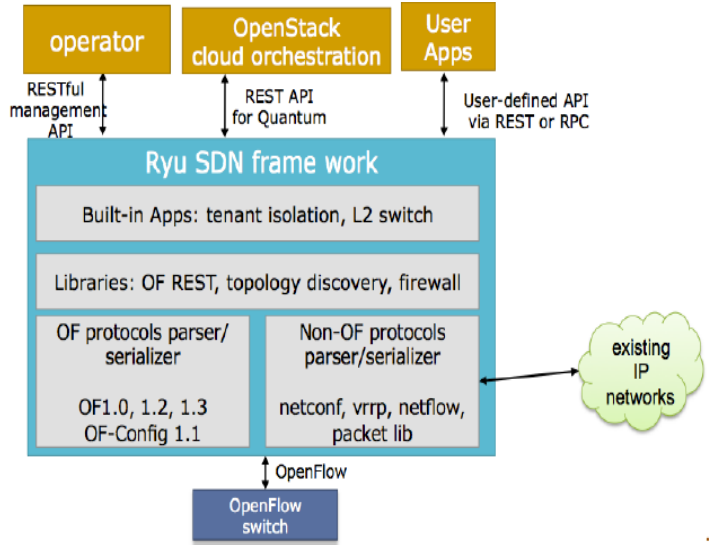

Gambar 3. Arsitektur dari Ryu Controller [8]

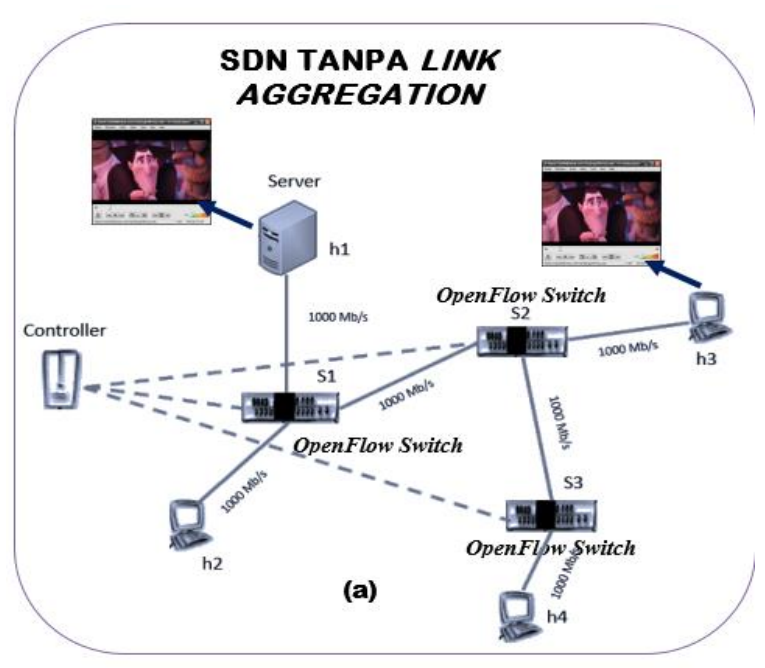

Gambar 4. Topologi jaringan SDN tanpa link aggregation

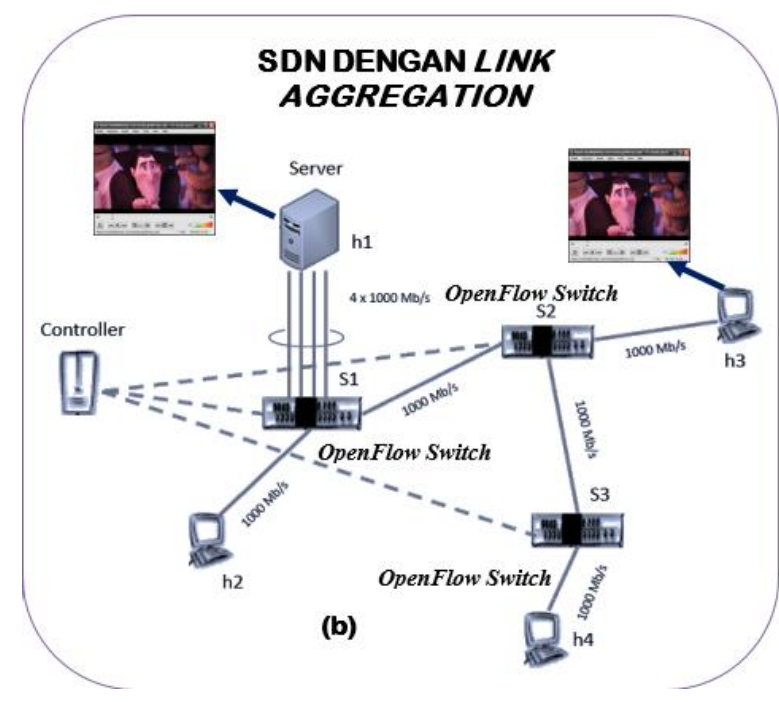

Gambar 5. Topologi jaringan SDN dengan link aggregation

\section{METODE PENELITIAN}

\subsection{Perancangan Sistem}

Penelitian ini menggunakan jaringan berbasis SDN, yang di-emulasi-kan menggunakan Mininet yang berjalan pada sistem operasi Linux Ubuntu. Controller yang digunakan pada penelitian ini adalah Ryu. Topologi jaringan yang digunakan adalah topologi jaringan data center sederhana, yang terdiri atas 3 buah host yang bertindak sebagai client, 1 buah host yang bertindak sebagai server layanan real-time video streaming, buah switch dengan OpenFlow v1.3.0. Seluruh link yang digunakan memiliki kapasitas $1000 \mathrm{Mb} / \mathrm{s}$, kecuali pada link antara server video dengan switch yang memiliki kapasitas $100 \mathrm{Mb} / \mathrm{s}$. Trafik video streaming memiliki teknik kompresi video H.264 yang dialirkan secara real-time ke host yang mengaksesnya.

Terdapat dua jenis topologi jaringan SDN yang digunakan, yakni pada Gambar 4 skenario jaringan SDN tanpa menggunakan link aggregation sehingga hanya ada link tunggal antara server layanan video streaming dengan OpenFlow switch, dan jaringan SDN Gambar 5 dengan menggunakan link aggregation yang terdiri atas 4 buah link fisik yang diikat menjadi satu buah link logika antara server layanan video streaming dengan OpenFlow switch, yang kemudian akan dibandingkan performansinya. Gambar 4 dan 5 menunjukkan topologi jaringan SDN tanpa link aggregation dan dengan link aggregation antara server dan OpenFlow switch.

\subsection{Skenario Penelitian}

Penelitian berupa perbandingan performansi antara jaringan SDN yang menerapkan konsep link aggregation dengan yang terhubung secara konvensional tanpa menggunakan link aggregation. Parameter performansi yang diukur diantaranya adalah throughput, jitter dan packet loss. Terdapat dua buah skenario, skenario pertama adalah variasi penambahan ukuran background traffic, yakni mulai tanpa adanya background traffic dalam jaringan, $200 \mathrm{Mb}, 400 \mathrm{Mb}, 600 \mathrm{Mb}$, hingga 800 $\mathrm{Mb}$ untuk dilihat performansinya terhadap nilai throughput, jitter dan packetloss dari client yang mengakses layanan video streaming secara realtime. Skenario kedua adalah pemutusan salah satu link fisik untuk dilihat pengaruh link aggregation terhadap redundansi jaringan terkait 
network availability. Standar yang digunakan sebagai acuan untuk mengetahui baik atau tidaknya performansi yang dihasilkan adalah Rekomendasi ITU-T G.1080, dimana throughput minimal yang direkomendasikan untuk kompresi H.264 adalah 1.75 Mbps dan jitter minimalnya adalah $50 \mathrm{~ms}$. Untuk packet loss, standar yang digunakan sebagai acuan adalah rekomendasi dari Cisco untuk QoS pada LAN, WAN, dan VPN [15], dimana nilai rekomendasi untuk layanan video streaming yang baik adalah diatas dibawah 5 persen.

\section{HASIL DAN PEMBAHASAN}

Bagian ini menampilkan data hasil emulasi menggunakan Mininet dan dijelaskan pengaruh ukuran background traffic terhadap beberapa parameter performansi yang diteliti on dan pemutusan salah satu link fisik sebagai bentuk uji redundansi dan availability dari jaringan.

\subsection{Variasi ukuran background traffic terhadap throughput}

Pada Tabel 1 dan Gambar 6 ditunjukan hubungan antara ukuran background traffic terhadap throughput dari sisi client yang melakukan video streaming secara real-time.

Tabel 1. Throughput Terhadap Ukuran Background Traffic

\begin{tabular}{|c|c|c|}
\hline \multirow{2}{*}{$\begin{array}{c}\text { Background } \\
\text { Traffic (Mb) }\end{array}$} & \multicolumn{2}{|c|}{ Throughput (Mbit/sec) } \\
\cline { 2 - 3 } & $\begin{array}{c}\text { Tanpa Link } \\
\text { aggregation }\end{array}$ & $\begin{array}{c}\text { Menggunakan } \\
\text { Link aggregation }\end{array}$ \\
\hline 0 & 1.668 & 2.153 \\
\hline 200 & 1.615 & 2.087 \\
\hline 400 & 1.469 & 1.98 \\
\hline 600 & 1.422 & 1.799 \\
\hline 800 & 1.416 & 1.697 \\
\hline
\end{tabular}

Dari Gambar 6 terlihat bahwa throughput mengalami penurunan seiring dengan bertambahnya ukuran background traffic. Kondisi tersebut karena kapasitas jalur yang digunakan semakin besar, yang membuat throughput untuk streaming layanan video mengecil. Terlihat, throughput mengalami penurunan hingga sebesar $45.43 \%$ di jaringan tanpa link aggregation serta penurunan sebesar $10.77 \%$ pada jaringan dengan menggunakan link aggregation di sisi server dan OpenFlow switch dari throughput sebelum diberi background traffic hingga diberi background traffic sebesar $800 \mathrm{Mb}$.

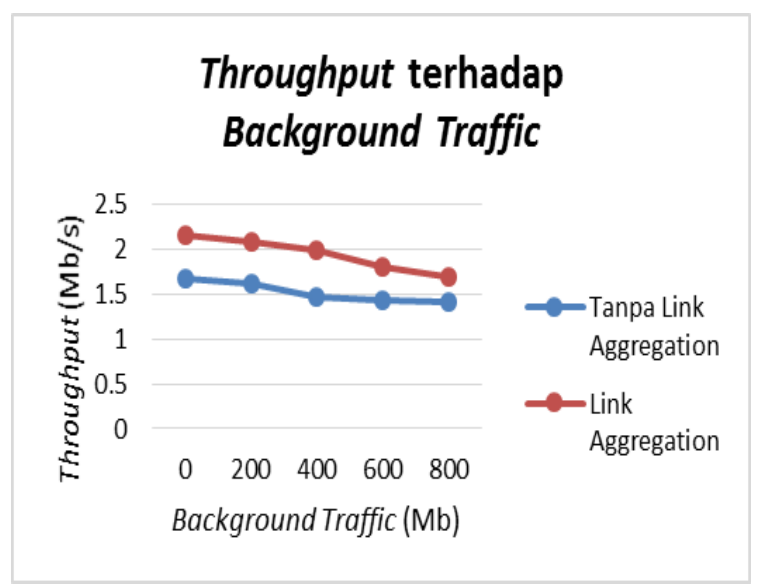

Gambar 6. Throughput terhadap ukuran background traffic

Pada Tabel 1 dan Gambar 6 terlihat bahwa throughput pada jaringan dengan menggunakan link aggregation lebih tinggi sebesar $22.53 \%$, $22.61 \%, 25.81 \%, 20.95 \%$, dan $16.56 \%$ dibandingkan dengan jaringan tanpa menggunakan link aggregation. Hal ini disebabkan karena kapasitas link pada jaringan dengan menggunakan link aggregation bertambah besar. Terdapat empat buah link fisik yang masing-masing memiliki kapasitas link 100 Mbps yang diikat menjadi satu membentuk suatu link logika yang berkapasitas 400 Mbps. Sehingga, throughput yang diterima akan menjadi lebih tinggi akibat kapasitas link dari server ke OpenFlow switch yang besar dibandingkan tanpa link aggregation. Sesuai dengan standar ITU-T G.1080, maka pada jaringan tanpa link aggregation untuk seluruh ukuran background traffic, nilai throughput yang dihasilkan dibawah standar, yakni 1.75 Mbps, sementara layanan video pada jaringan dengan link aggregation saat tidak ada background traffic dan saat ada background traffic dengan ukuran $200 \mathrm{Mb}, 400 \mathrm{Mb}$,dan 600 $\mathrm{Mb}$ menghasilkan throughput yang diatas nilai standar rekomendasi ITU-T G.1080. Namun, saat ukuran background traffic meningkat menjadi $800 \mathrm{Mb}$, nilai throughput yang dihasilkan dibawah standar akibat kapasitas link yang padat oleh trafik sehingga mempengaruhi kualitas video yang ditampilkan di sisi client. 


\subsection{Variasi ukuran background traffic terhadap jitter}

Pada Tabel 2 dan Gambar 7 ditunjukkan hubungan antara ukuran background traffic terhadap jitter dari sisi client yang melakukan video streaming secara real-time.

Tabel 2. Jitter Terhadap Ukuran Background Traffic

\begin{tabular}{|c|c|c|}
\hline \multirow{2}{*}{$\begin{array}{c}\text { Background } \\
\text { Traffic (Mb) }\end{array}$} & \multicolumn{2}{|c|}{ Jitter (ms) } \\
\cline { 2 - 3 } & $\begin{array}{c}\text { Tanpa Link } \\
\text { aggregation }\end{array}$ & $\begin{array}{c}\text { Menggunakan } \\
\text { Link aggregation }\end{array}$ \\
\hline 0 & 9,96 & 5,67 \\
\hline 200 & 7,52 & 5,75 \\
\hline 400 & 9,29 & 5,83 \\
\hline 600 & 10,27 & 6,15 \\
\hline 800 & 13,24 & 6,31 \\
\hline
\end{tabular}

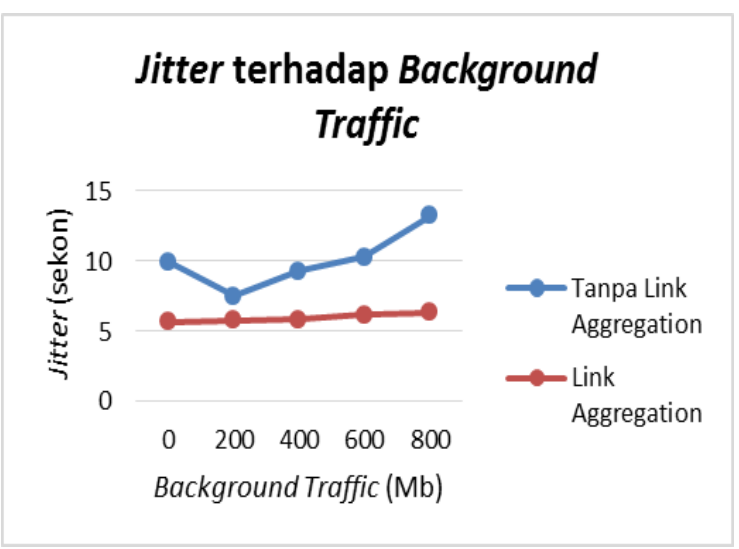

Gambar 7. Jitter terhadap ukuran background traffic

Dari Gambar 7 terlihat bahwa jitter secara keseluruhan mengalami kenaikan seiring dengan bertambahnya ukuran background traffic. Kondisi ini dilatarbelakangi semakin tingginya background traffic maka trafik menjadi padat saat melewati suatu link, dimana saat trafik sedang padat, maka jalur paket akan terhambat yang memunculkan delay yang nilanya bervariasi. Variasi delay ini yang menghasilkan nilai jitter. Untuk aplikasi seperti video real-time maka jitter harus diperhatikan.

Jitter di SDN tanpa link aggregation dan dengan link aggregation masing-masing meningkat sebesar $32.93 \%$ dan $11.28 \%$ dari keadaan tanpa background traffic sampai pada penambahan background traffic hingga sebesar $800 \mathrm{Mb}$.

Pada Tabel 2 dan Gambar 7 terlihat bahwa nilai jitter yang berasal dari lingkungan SDN dengan link aggregation lebih rendah dibandingkan dengan nilai jitter pada jaringan SDN tanpa metode link aggregation, yakni lebih rendah sebesar $43.07 \%, 23.53 \%, 37.24 \%$, $40.11 \%$, dan $52.34 \%$ pada masing-masing keadaan jaringan tanpa background traffic, dengan adanya background traffic berukuran $200 \mathrm{Mb}, 400 \mathrm{Mb}, 600 \mathrm{Mb}$, dan $800 \mathrm{Mb}$. Hal ini disebabkan karena kapasitas link setelah mengalami agregasi meningkat menjadi empat kali lipat kapasitas sebelumnya sehingga penambahan background traffic yang mengalir dari server ke client tidak menghasilkan jitter sebesar kondisi jaringan tanpa adanya link aggregation antara server dan OpenFlow switch yang membuat link fisik tersebut kewalahan menangani trafik data yang semakin besar. Mengacu pada Rekomendasi Standar ITU-T G.1080, nilai jitter untuk keadaan jaringan SDN tanpa link aggregation maupun dengan adanya link aggregation masih bisa ditoleransi oleh jaringan karena memiliki nilai jitter dibawah 50 milisekon.

\subsection{Variasi ukuran background traffic terhadap packet loss}

Pada Tabel 3 dan Gambar 8 nilai packet loss di jaringan SDN dengan skenario link aggregation lebih rendah dibandingkan dengan nilai packet loss pada jaringan SDN tanpa link aggregation, yakni lebih rendah sebesar $100 \%$, $89.06 \%, 84.79 \%, 73.93 \%$, dan $58.93 \%$ pada masing-masing keadaan jaringan tanpa background traffic, dengan adanya background traffic berukuran $200 \mathrm{Mb}, 400 \mathrm{Mb}, 600 \mathrm{Mb}$, dan $800 \mathrm{Mb}$. Hal ini disebabkan karena kapasitas link setelah mengalami agregasi meningkat menjadi empat kali lipat kapasitas sebelumnya yang membuat link tidak sepadat seperti pada jaringan tanpa adanya link aggregation, sehingga penambahan background traffic yang mengalir dari server ke client tidak menghasilkan packet loss sebesar kondisi jaringan tanpa adanya link aggregation antara server dan OpenFlow switch yang membuat link fisik tersebut kewalahan menangani trafik data yang semakin besar. 
Tabel 3. Packet Loss Terhadap Ukuran Background Traffic

\begin{tabular}{|c|c|c|}
\hline \multirow{2}{*}{$\begin{array}{c}\text { Background } \\
\text { Traffic (Mb) }\end{array}$} & \multicolumn{2}{|c|}{ Packet Loss (ms) } \\
\cline { 2 - 3 } & $\begin{array}{c}\text { Tanpa Link } \\
\text { aggregation }\end{array}$ & $\begin{array}{c}\text { Menggunakan } \\
\text { Link aggregation }\end{array}$ \\
\hline 0 & 2,6 & 0 \\
\hline 200 & 11,52 & 1,26 \\
\hline 400 & 14,27 & 2,17 \\
\hline 600 & 16,19 & 4,22 \\
\hline 800 & 19,24 & 7,9 \\
\hline
\end{tabular}

Mengacu pada standar Cisco terhadap layanan video streaming yang digunakan, nilai packet loss pada kondisi tanpa link aggregation ketika diberikan background traffic tidak memenuhi standar sehingga video yang dihasilkan kurang baik. Untuk kondisi dengan link aggregation, nilai packet loss nya memenuhi standar minimum yang ditetapkan pada ukuran background traffic sebesar $200 \mathrm{Mb}$, $400 \mathrm{Mb}$, dan $600 \mathrm{Mb}$.

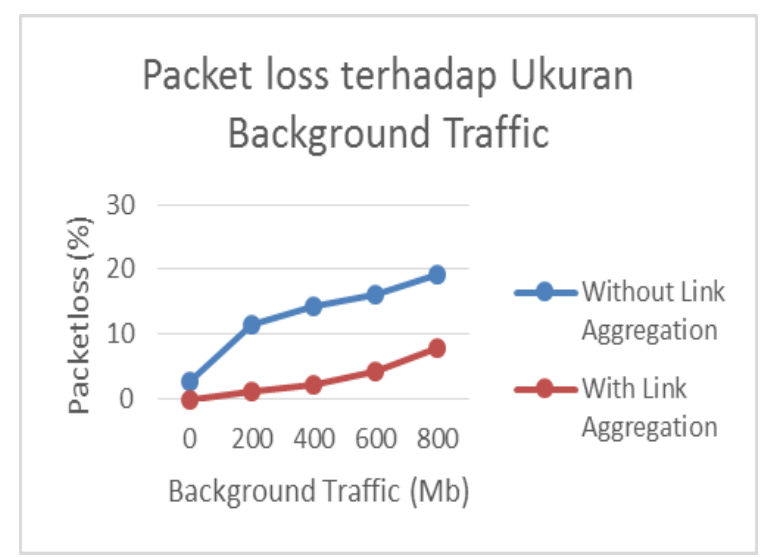

Gambar 8. Packet Loss terhadap ukuran background traffic

\subsection{Uji redudansi dan availability jaringan}

Uji redundansi dan availability jaringan dilakukan untuk mengetahui jaminan suatu jaringan mampu menghadirkan komunikasi yang dapat diandalkan dalam segala kondisi, bahkan di saat terjadi gangguan sekalipun. Pada skenario ini, gangguan komunikasi dihadirkan dalam bentuk pemutusan link fisik antara server layanan video streaming dengan OpenFlow switch.

Hasilnya, layanan video masih bisa dapat diterima dengan baik di sisi client walaupun salah satu link fisik putus pada jaringan SDN dengan link aggregation. Namun, akibat pemutusan satu link fisik yang sebelumnya terikat dengan link fisik lain membentuk suatu kanal logika menyebabkan throughput dan jitter dari sisi client yang mengakses layanan video streaming menurun. Tabel 4 dan Gambar 8 menunjukkan throughput untuk variasi ukuran background traffic pada saat salah satu link fisik yang tergabung dalam kanal logika yang teragregasi diputus.

Tabel 4. Throughput Terhadap Ukuran Background Traffic pada kondisi salah satu Link fisik terputus

\begin{tabular}{|c|c|c|}
\hline \multirow{2}{*}{$\begin{array}{c}\text { Background } \\
\text { Traffic } \\
\text { (Mb) }\end{array}$} & \multicolumn{2}{|c|}{ Throughput (Mbit/sec) } \\
\cline { 2 - 3 } & $\begin{array}{c}\text { Link aggregation } \\
\text { sesudah putus }\end{array}$ & $\begin{array}{c}\text { Link } \\
\text { aggregation } \\
\text { Sebelum putus }\end{array}$ \\
\hline 0 & 1,889 & 1,932 \\
\hline 200 & 1,876 & 1,905 \\
\hline 400 & 1,799 & 1,878 \\
\hline 600 & 1,759 & 1,829 \\
\hline 800 & 1,723 & 1,736 \\
\hline
\end{tabular}

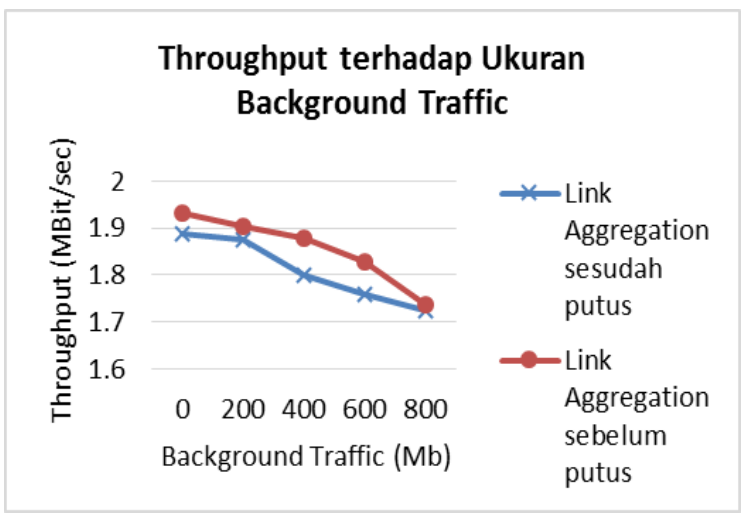

Gambar 9. Throughput terhadap ukuran background traffic pada jaringan SDN dengan kondisi salah satu link fisik putus

Pada Tabel 4 dan Gambar 9, nilai throughput pada jaringan SDN dengan menggunakan link aggregation saat terjadi pemutusan salah satu link fisik lebih kecil sebesar $2.22 \%, 1.52 \%, 4.20 \%, 3.82 \%$, dan $0.74 \%$ dari nilai throughput pada jaringan SDN dengan menggunakan link aggregation tanpa pemutusan salah satu link fisik. Hal ini disebabkan karena kapasitas link menurun akibat terjadinya pemutusan link fisik yang sebelumnya 
teragregasi dan terikat dengan link fisik lain membentuk satu kanal logika, sehingga kapasitas link setelah terjadi pemutusan adalah sebesar $300 \mathrm{Mbps}$. Dari nilai throughput yang didapat saat terjadi pemutusan, terlihat bahwa throuhput yang memenuhi rekomendasi standar ITU-T G.1080 hanya tercapai pada saat tanpa adanya background traffic.

Tabel 5. Jitter Terhadap Ukuran Background Traffic pada kondisi salahsatu Link fisik terputus

\begin{tabular}{|c|c|c|}
\hline \multirow{2}{*}{$\begin{array}{c}\text { Background } \\
\text { Traffic } \\
\text { (Mb) }\end{array}$} & $\begin{array}{c}\text { Jink } \\
\text { aggregation } \\
\text { sesudah putus }\end{array}$ & $\begin{array}{c}\text { Link } \\
\text { aggregation } \\
\text { Sebelum putus }\end{array}$ \\
\hline 0 & 6,12 & 5,67 \\
\hline 200 & 6,48 & 5,75 \\
\hline 400 & 6,73 & 5,83 \\
\hline 600 & 7,04 & 6,15 \\
\hline 800 & 8,77 & 6,31 \\
\hline
\end{tabular}

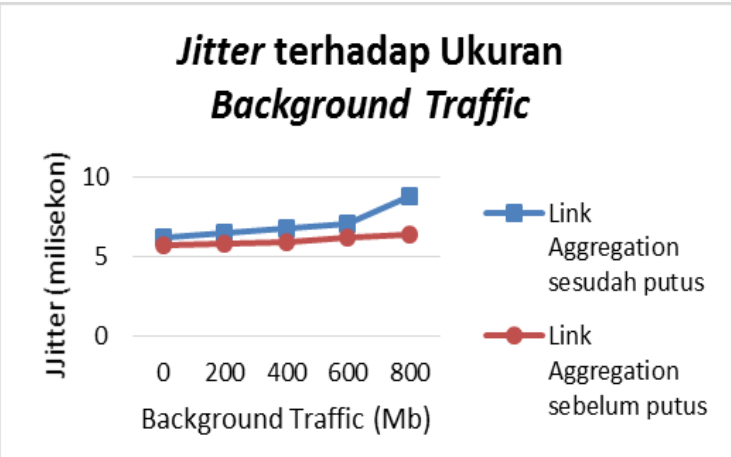

Gambar 10. Jitter terhadap ukuran background traffic pada jaringan SDN dengan kondisi salah satu link fisik putus

Pada Tabel 5 dan Gambar 10, nilai jitter pada jaringan SDN dengan menggunakan link aggregation saat terjadi pemutusan salah satu link fisik lebih besar sebesar 7.93\%, 12.69\%, $15.43 \%$, $14.47 \%$, dan $38.98 \%$ dari nilai jitter pada jaringan SDN dengan menggunakan link aggregation tanpa pemutusan salah satu link fisik. Hal ini disebabkan karena kapasitas link menurun akibat terjadinya pemutusan link fisik yang sebelumnya teragregasi dan terikat dengan link fisik lain membentuk satu kanal logika, semakin tinggi nilai background traffic maka semakin padat trafik yang melewati suatu link, oleh sebab itu kondisi trafik padat, maka perjalanan paket tersendat. Dari nilai jitter yang didapat saat terjadi pemutusan, terlihat bahwa seluruh jitter pada seluruh ukuran background traffic memenuhi rekomendasi standar ITU-T G.1080 background traffic.

Tabel 6. Packet Loss Terhadap Ukuran Background Traffic pada kondisi salahsatu Link fisik terputus

\begin{tabular}{|c|c|c|}
\hline \multirow{2}{*}{$\begin{array}{c}\text { Background } \\
\text { Traffic (Mb) }\end{array}$} & \multicolumn{2}{|c|}{ Packet loss (\%) } \\
\cline { 2 - 3 } & $\begin{array}{c}\text { Link } \\
\text { aggregation } \\
\text { sesudah putus }\end{array}$ & $\begin{array}{c}\text { Link } \\
\text { aggregation } \\
\text { Sebelum putus }\end{array}$ \\
\hline 0 & 0 & 0 \\
\hline 200 & 1,58 & 1,26 \\
\hline 400 & 2,42 & 2,17 \\
\hline 600 & 4,88 & 4,22 \\
\hline 800 & 9,23 & 7,9 \\
\hline
\end{tabular}

\section{Packet loss terhadap Ukuran Background Traffic}

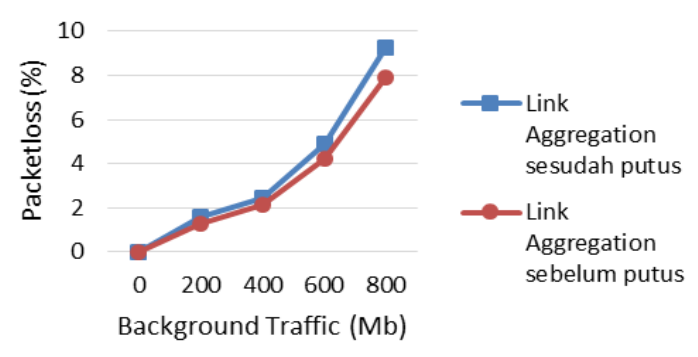

Gambar 11. Packet Loss terhadap ukuran background traffic pada jaringan SDN dengan kondisi salah satu link fisik putus

Pada Tabel 6 dan Gambar 11, nilai packetloss pada jaringan SDN dengan menggunakan link aggregation saat terjadi pemutusan salah satu link fisik lebih besar sebesar 0\%, 25.40\%, $11.52 \%, 15.64 \%$, dan $16.83 \%$ dari nilai packet loss pada jaringan SDN dengan menggunakan link aggregation tanpa pemutusan salah satu link fisik. Hal ini disebabkan karena kapasitas link menurun akibat terjadinya pemutusan link fisik yang sebelumnya teragregasi dan terikat dengan link fisik lain membentuk satu kanal logika, semakin tinggi nilai background traffic maka semakin padat trafik yang melewati suatu link, dimana saat trafik yang lewat banyak, maka akan berdampak 
ke terhambatnya perjalanan paket akan terhambat dan mengalami kehilangan paket. Dari nilai packet loss yang didapat saat terjadi pemutusan, terlihat bahwa seluruh packet loss pada seluruh ukuran background traffic telah memenuhi standar minimumnya yaitu dibawah 5\% pada skenario ada background traffic dan skenario melewatkan background traffic sebesar $200 \mathrm{Mb}, 400 \mathrm{Mb}$, dan $600 \mathrm{Mb}$.

Tabel 7. Waktu pemulihan jaringan saat salah satu link terputus

\begin{tabular}{|c|c|}
\hline $\begin{array}{c}\text { Background } \\
\text { Traffic } \\
\text { (Mb) }\end{array}$ & $\begin{array}{c}\text { Waktu Pemulihan Jaringan } \\
\text { (sekon) }\end{array}$ \\
\hline 0 & 66,04 \\
\hline 200 & 74,74 \\
\hline 400 & 79,52 \\
\hline 600 & 91,07 \\
\hline 800 & 101,23 \\
\hline
\end{tabular}

Tabel 7 menunjukkan waktu yang dibutuhkan untuk melakukan pemulihan jaringan bila salah satu link diputus untuk setiap background traffic yang diberikan. Dengan nilai background traffic yang diberikan sebesar 200 $\mathrm{Mb}, 400 \mathrm{Mb}, 600 \mathrm{Mb}$, dan $800 \mathrm{Mb}$. Terlihat bahwa semakin tinggi background traffic yang dilewatkan maka akan membutuhkan waktu lama untuk melakukan pemulihan jaringan. Dari data yang diperoleh, waktu pemulihan jaringan telah mengalami kenaikan sekitar $34.76 \%$ dari sebelum diberikan background traffic sampai diberikan background traffic sebesar $800 \mathrm{Mb}$.

\section{KESIMPULAN}

Berdasarkan penelitian yang dilakukan, diperoleh kesimpulan bahwa jaringan SDN yang memanfaatkan konsep link aggregation menghadirkan komunikasi data yang cepat dari sisi throughput, menghasilkan jitter yang rendah serta menghasilkan packetloss yang kecil dibandingkan dengan jaringan SDN tanpa memanfaatkan konsep link aggregation. Hal ini dilakukan untuk menambah kualitas layanan yang disediakan dan dinikmati oleh client, sehingga akan menambah nilai lebih dari sisi Quality of Experience pelanggan. Selain itu, jaringan dengan link aggregation menjamin keberlangsungan proses komunikasi meskipun terdapat salah satu link yang putus, yaitu dengan melihat waktu pemulihan jaringan yang cepat, sehingga meningkatkan redundansi dan kehandalan jaringan yang tentunya akan menjadi nilai lebih bagi setiap penyelenggara jaringan untuk melayani konsumennya.

\section{DAFTAR PUSTAKA}

[1] McKeown, N., T. Anderson, H. Balakrishnan, G. Parulkar, L. Peterson, J. Rexford, S. Shenker et al. 2008. OpenFlow: Enabling innovation in campus networks. SIGCOMM Comput. Commun. Rev. 38(2):69-74.

[2] Steinbacher. $M$ and Bredel. M, "LACP Meets OpenFlow - Seamless Link," University of Applied Sciences, Kufstein Tirol, Austria.

[3] Jeffree. T, "Strawman/D21/2: Changes/Additions to 802.3 required in order to specify Link Aggregation," Contribution to the November '98 Link Aggregation Meeting, IEEE, 1998.

[4] C. Balakrishnan och M. Manikandan, "Link Aggregation Strategies," International Journal of Advanced Research in Computer Engineering \& Technology (IJARCET), vol. 1, nr 10, pp. 199-203, 2012.

[5] "Link Aggregation Control Protocol (LACP) (802.3ad) for Gigabit Interfaces," Cisco, March 2007. [Online]. Available: https://www.cisco.com/c/en/us/td/docs/io s/12_2sb/feature/guide/gigeth.html

[6] B. Zdrnja, "Malicious JavaScript Insertion through ARP Poisoning Attacks," IEEE Security \& Privacy, vol. 7, nr 3, 2009.

[7] SysKonnect GmbH, White paper. "Link Aggregation according to IEEE Standard 802.3ad", Okt 2002.

[8] D. Pemberton, A. Linton S. and Russel, "Ryu OpenFlow Controller," University of Oregon.

[9] Benson. T, Akella. A, and Maltz. D, "Unraveling the complexity of network management," eProceedings of the 6th USENIX Symposium on Networked systems design and implementation, Berkeley, 2009.

[10] Ghodsi, A., S. Shenker, T. Koponen, A. Singla, B. Raghavan and J. Wilcox, "Intelligent design enables architectural 
evolution," Proceedings of the 10th ACM Workshop on Hot Topics in Networks, New York, pp. 3:1-3:6, 2011.

[11] N. Feamster and H. Balakrishnan, "Detecting BGP configuration faults with static analysis," Proceedings of the 2nd conference on Symposium on Networked Systems Design \& Implementation Volume 2, Berkeley, California, 2005.

[12] K. Butler, T. Farley, P. McDaniel och a. J. Rexford, "A survey of BGP security issues and solutions," Proceedings of the IEEE, 2010.

[13] D. Kreutz, F. M. Ramos, P. Verissimo, C. Rothenberg, S. Azdolmolky and S. Uhlig, "Software Defined Networking: A Comprehensive Survey," Proceedings of the IEEE, vol. 103, nr 1, pp. 14-76, 2015.
[14] ONF, "Open networking foundation," 2014. [Online]. Available: https://www.opennetworking.org/.

[15] T. Szigeti and H. Christina, "QoS Requirements of Video," End-to-End QoS Network Design: Quality of Service in LANs, WANs, and VPNs, Cisco Press, 2004.

\section{Biodata Penulis}

Rohmat Tulloh, S.T., M.T, staf pengajar pada Program Studi D3 Teknik Telekomunikasi, Fakultas Ilmu Terapan, Universitas Telkom. Ketertarikan dalam bidang Jaringan Komputer khususnya Software Defined Network dan Internet of Things. 